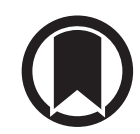

CrossMark

\section{Respiratory irritants in e-cigarette refill liquids across nine European countries: a threat to respiratory health?}

\author{
To the Editor:
}

The rapid expansion of the e-cigarette market across European countries has raised a number of concerns within the scientific community $[1,2]$. The most recent data from across the European Union revealed a substantial increase in e-cigarette experimentation, with $15 \%$ of European citizens reporting having tried e-cigarettes in 2017, representing a 7.0\% increase since 2012 [3]. Annual e-cigarette sales in Europe have reached EUR 1.33 billion, and are projected to reach over EUR 10 billion by 2020 [4].

It is important to note that despite the increasing popularity of e-cigarettes, there is new and emerging evidence documenting the potential health risks of using these products, particularly with regard to respiratory health. Previous research identified an increase in lung flow resistance after 5 min of e-cigarette product use and an associated decrease in fractional exhaled nitric oxide ( $F \mathrm{eNO}$ ) concentrations [5]. Several studies have indicated that the chemical substances and ultrafine particles of in e-cigarette vapour can cause dry cough and irritation of the pharynx and upper and lower respiratory system, and are also potentially toxic and carcinogenic [6,7]. Furthermore, glycol and glycerol vapours and other mist components of e-cigarettes have been found to cause dryness of the mucous membranes and irritation of the upper airway [6]. Flavours used in e-cigarette liquids can also have an acute cytotoxic effect on respiratory cells, with menthol, coffee and strawberry flavours found to affect the overall cytotoxicity of the refill liquids [8]. Kosmider et al. [9] found that e-cigarette users are exposed to significant amounts of benzaldehyde, which is a known respiratory irritant, and those who use cherry-flavoured e-cigarette products may inhale significantly higher doses of benzaldehyde compared with users of other flavours. The latest revision to the European Tobacco Products Directive (TPD) has set out robust safety and quality standards for manufacturers and importers of e-cigarettes sold in the EU, in order to ensure a high level of health protection for European citizens [10]. The TPD mandates that, except for nicotine, ingredients used in the nicotine-containing liquid should not pose a risk to human health in heated or unheated form [10]. With this in mind, we aimed to identify and, where possible, quantify the existence of potential respiratory irritants within e-cigarette refill liquids, across nine European Union member states (EU MS).

Within the context of the Horizon 2020 EUREST-PLUS project, in 2016 we identified and purchased 122 randomly selected samples from the most popular e-cigarette brands in nine EU MS. The most popular brands were identified based on either sales data (Euromonitor) or on website visits if brand data were not available (www.alexa.com). Based on this methodology, a comprehensive list of all products available in the five most popular companies was generated and three products were then randomly selected from each company $(\mathrm{n}=122)$ for chemical analysis.

The analysis was performed by a previously validated gas chromatography-mass spectrometry (GC-MS) and liquid chromatography-mass spectrometry (LC-MS) method, and results were compared with the Globally Harmonised Classification System (GHS) classification for respiratory irritants [11, 12]. The e-liquid samples were analysed for their flavours and additive content. For the analysis of ethyl hexanoate, limonene, a-terpinolene, linalool, menthol, a-damascone, b-damascone, a-ionone and b-ionone, a GC-MS system equipped with an AOC-5000 robotic auto sampler using a $\mathrm{SLB}^{\mathrm{tm}}-5 \mathrm{~ms}$ (Supelco, Bellefonte, PA, USA) capillary column ( $30 \mathrm{~m}$ length, $0.25 \mathrm{~mm}$ internal diameter, $0.25 \mu \mathrm{m}$ film thickness) was used. Methyl

@ERSpublications

Respiratory irritants within e-cigarette refill liquids are a cause for concern for respiratory health http://ow.ly/454g30gK09m

Cite this article as: Vardavas C, Girvalaki C, Vardavas A, et al. Respiratory irritants in e-cigarette refill liquids across nine European countries: a threat to respiratory health? Eur Respir J 2017; 50: 1701698 [https://doi.org/10.1183/13993003.01698-2017]. 
TABLE 1 Evaluation of potential respiratory irritants among popular e-cigarette refill liquids ( $n=122)$, across nine European Union member states in 2016

\begin{tabular}{|c|c|c|c|c|}
\hline \multirow[t]{2}{*}{ Substance } & \multirow[t]{2}{*}{ Positive samples $\%$} & \multicolumn{3}{|c|}{ Detected values $\%(w / w)$} \\
\hline & & Mean & Minimum & Maximum \\
\hline Menthol & 41.0 & 0.1222 & 0.0001 & 0.4991 \\
\hline Ethyl maltol & 36.9 & 0.4409 & 0.0043 & 7.0960 \\
\hline Linalool & 31.1 & 0.0268 & 0.0004 & 0.2630 \\
\hline Methyl cyclopentanolone & 26.2 & 0.2642 & 0.0091 & 2.5067 \\
\hline$\beta$-damascone & 18.9 & 0.0070 & 0.0002 & 0.0742 \\
\hline Ethyl vanillin & 18.0 & 0.1714 & 00057 & 0.9135 \\
\hline b-lonone & 10.7 & 0.0029 & 0.0005 & 0.0076 \\
\hline Acetyl pyrazine & 9.0 & 0.0466 & 0.0159 & 0.1067 \\
\hline a-lonone & 9.0 & 0.0048 & 0.0005 & 0.0120 \\
\hline Ethyl hexanoate & 8.2 & 0.0124 & 0.0009 & 0.0554 \\
\hline 2,5 dimethylpyrazine & 4.1 & 0.0077 & 0.0007 & 0.0197 \\
\hline$\alpha$-damascone & 2.5 & 0.0029 & 0.0002 & 0.0078 \\
\hline 3,4 dimethoxy benzaldehyde & 1.6 & 0.0257 & 0.0156 & 0.0359 \\
\hline Limonene & 0.8 & 0.0001 & 0.0001 & 0.0001 \\
\hline
\end{tabular}

cyclopentenolone, ethyl maltol, 2,5-dimethylpyrazine, ethyl vanillin and 3,4-dimethoxybenzaldehyde compounds were determined and quantified by LC-MS.

In total, 246 different flavours and additives were detected among the samples tested, with the most common flavour substance detected being menthol (41.0\%), followed by ethyl maltol (36.9\%), linalool (31.1\%), methyl cyclopentanolone (26.2\%), beta-damascone (18.9\%), ethyl vanillin (18.0\%), b-ionone (10.7\%), and acetyl pyrazine and a-ionone (9.0\%) (table 1). The mean, minimum and maximum detected values $(\%, w / w)$ of the above were quantified (table 1$)$.

Moreover, all of the refill liquid samples analysed (122/122) were found to have additives that are classified to have some level of danger/risk of hazard based on the GHS classification. Specifically, both methyl cyclopentanolone and a-ionone may cause allergy or asthma symptoms or breathing difficulties if inhaled, while methyl cyclopentanolone is also able to cause respiratory irritations [13]. Other substances such as acetyl pyrazine, ethyl vanillin and menthol have also been found to cause respiratory irritation [13]. In addition to the role of the above substances as respiratory irritants based on the GHS classification, all have warnings about a wide range of effects, including skin, eye and respiratory irritation; allergies; harmful or even fatal effects if swallowed; induction of drowsiness or dizziness; suspected damage to fertility or the foetus; toxicity to aquatic life; and flammability [12].

Our study tested a randomly selected sample of e-cigarette liquids, based on available databases, immediately prior to the introduction of the TPD. Despite the large sample tested, we did not test all liquids available in Europe; it is possible that additional respiratory irritants may be contained in e-cigarette refills, and our results should be understood in the context of this limitation.

To our knowledge, this is the first attempt to identify the existence of respiratory irritants within e-cigarette refill liquids across EU MS, an area of potential concern for respiratory health. Our findings indicate potentially hazardous substances in e-cigarettes, contrary to Article 20 of the TPD, which clearly states that with the exception of nicotine, only ingredients that do not pose a risk to human health in heated or unheated form should be used in the liquid [10]. For this reason and in order to ensure the protection of European consumer's health, monitoring of e-cigarette additives is necessary and should be addressed urgently.

Constantine Vardavas ${ }^{1,2}$, Charis Girvalaki ${ }^{1}$, Alexander Vardavas ${ }^{1}$, Sophia Papadakis ${ }^{1,3}$, Manolis Tzatzarakis ${ }^{1}$, Panagiotis Behrakis ${ }^{2}$ and Aristidis Tsatsakis ${ }^{1}$

${ }^{1}$ Laboratory of Toxicology, Faculty of Medicine, University of Crete, Heraklion, Greece. ${ }^{2}$ Institute of Public Health of the American College of Greece, Athens, Greece. ${ }^{3}$ Division of Prevention and Rehabilitation, University of Ottawa Heart Institute, Ottawa, ON, Canada.

Correspondence: Constantine Vardavas, University of Crete, Heraklion, Greece. E-mail: vardavas@tobcontrol.eu

Received: Aug 192017 | Accepted: Sept 192017

Support statement: This work was supported by a grant from the European Commission (Horizon2020 HCO-6-2015; EUREST-PLUS: 681109; Vardavas). Funding information for this article has been deposited with the Crossref Funder Registry.

Conflict of interest: None declared. 


\section{References}

1 Filippidis FT, Laverty AA, Gerovasili V, et al. Two-year trends and predictors of e-cigarette use in 27 European Union member states. Tobacco Control 2017; 26: 98-104.

2 Zhu SH, Sun JY, Bonnevie E, et al. Four hundred and sixty brands of e-cigarettes and counting: implications for product regulation. Tob Control 2014; 23: Suppl. 3, iii3-iii9.

3 European Commission. Special Eurobarometer 458: Attitudes of Europeans towards tobacco and electronic cigarettes. Brussels, European Union, 2017. Available from: http://ec.europa.eu/commfrontoffice/publicopinion/ index.cfm/Survey/getSurveyDetail/instruments/SPECIAL/surveyKy/2146 Date last accessed: August 2017. Date last updated: May 2017.

$4 \quad$ Nasdaq Research and Markets. Europe \$1.33 Billion E-cigarette and Vaporizer Device \& Aftermarket Report 2017: Vape Shop Analysis and Forecasts 2016-2022. https:/globenewswire.com/news-release/2017/02/24/927549/0/en/ Europe-1-33-Billion-E-cigarette-and-Vaporizer-Device-Aftermarket-Report-2017-Vape-Shop-Analysis-and-Forecasts2016-2022.html Date last accessed: August 2017. Date last updated: February 24, 2017.

5 Vardavas CI, Anagnostopoulos N, Kougias M, et al. Short-term pulmonary effects of using an electronic cigarette: impact on respiratory flow resistance, impedance, and exhaled nitric oxide. Chest 2012; 141: 1400-1406.

6 Callahan-Lyon P. Electronic cigarettes: human health effects. Tob Control 2014; 23: Suppl. 2, ii36-ii40.

7 Goniewicz ML, Knysak J, Gawron M. Levels of selected carcinogens and toxicants in vapour from electronic cigarettes. Tob Control 2014; 23: 133-139.

8 Leigh NJ, Lawton RI, Hershberger PA, et al. Flavourings significantly affect inhalation toxicity of aerosol generated from electronic nicotine delivery systems (ENDS). Tob Control 2016; 25: Suppl. 2, ii81-ii87.

9 Kosmider L, Sobczak A, ProkopowiczA, Kurek J, et al. Cherry-flavoured electronic cigarettes expose users to the inhalation irritant, benzaldehyde. Thorax 2016; 71: 376-377.

10 Directive 2014/40/EU of the European Parliament and of the Council of 3 April 2014 on the approximation of the laws, regulations and administrative provisions of the Member States concerning the manufacture, presentation and sale of tobacco and related products and repealing Directive 2001/37/EC. Available from: http://eur-lex.europa.eu/ legal-content/en/TXT/?uri=CELEX\%3A32014L0040 Date last accessed: August 2017. Date last updated: April 2014.

11 Kavvalakis PM, Stivaktakis DP, Tzatzarakis MN, et al. Multi-component analysis of replacement liquids of electronic cigarettes using chromatographic techniques. J Anal Toxicol 2015; 39: 262-269.

12 United Nations Economic Commission for Europe. Globally Harmonized System of Classification and Labelling of Chemicals (GHS). New York, United Nations, 2007. Available from: http://www.unece.org/trans/danger/publi/ ghs/ghs_rev02/02files_e.html Date last accessed: August 2017. Date last updated: 2011.

13 NCBI. PubChem Compound. https://pubchem.ncbi.nlm.nih.gov/compound Date last accessed: August 2017. 